\title{
Satisfação dos Moradores Cadastrados com os Serviços Prestados pelos Programas Saúde da Família da Lomba do Pinheiro, de Porto Alegre - RS
}

Satisfaction of Inhabitants Enrolled at the Services Provided by Lomba Family Health Programs of Lomba do Pinheiro District in Porto Alegre - $R S$

\author{
SILVA, Alexandre Emidio Ribeiro* \\ DREHMER, Tania Maria**
}

\begin{abstract}
RESUMO
O presente trabalho foi uma pesquisa qualitativa que teve como objetivo avaliar a satisfação dos moradores cadastrados no Centro de Saúde da Lomba, onde funcionam as unidades do Programa Saúde da Família - PSF, do bairro Lomba do Pinheiro na cidade de Porto Alegre - RS, em relação ao serviço que é prestado pela equipe de saúde comparado com os que lhes foram prestados em algum momento da vida. Também foram abordadas com os moradores as questões referentes à sua participação e ao seu conhecimento do Conselho de Saúde. Os dados da pesquisa foram coletados através de entrevistas semi - estruturas com perguntas abertas. Foram entrevistados sete moradores cadastrados do PSF. Verificou-se, através da análise das entrevistas, que o trabalho prestado pela equipe do PSF foi considerado muito bom quando comparado com os outros serviços com que tiveram contato. A melhora da qualidade do serviço foi relacionada à diminuição das filas para o acesso e à presença dos agentes comunitários, que através das visitas domiciliares acompanham sua saúde. Estas em nenhum momento foram consideradas como invasão de privacidade. Um ponto considerado negativo refere-se à dificuldade do acesso aos serviços de saúde de média e alta complexidade, o que impede a resolução dos problemas de saúde da comunidade. Os moradores consideram sua saúde como boa. Contudo, pela análise de suas respostas o fato de ter boa saúde está relacionado à ausência de sintomas de doenças. Em relação ao Conselho de Saúde, os moradores cadastrados disseram que nunca os profissionais da equipe de saúde conversaram sobre sua importância ou esclareceram como poderiam dele participar.
\end{abstract}

PALAVRAS CHAVES:

Pesquisa Qualitativa. Pesquisa sobre Serviço de Saúde. Programa Saúde da Família

\section{INTRODUCÃO}

Em 1994, iniciou-se o Programa Saúde da Família - PSF, tendo como referenciais os princípios do Sistema Único de Saúde SUS, dentre esses: a integralidade, a universalidade e a eqüidade, e tendo como objetivo fortalecer as ações em nível da atenção básica (MARQUES; MENDES, 2002; BRASIL, 2000).

O Programa Saúde da Família - PSF foi o resultado das ações do Governo Federal, através do Ministério da Saúde, para tornar possível a política voltada para a atenção básica, como foi proposto na Declaração de Alma-Ata, em 1978 (Organização Mundial de Saúde, 2004), e pela $9^{\mathrm{a}}$ Conferência Nacional de Saúde, em 1992 (BRASIL, 2004).

No Brasil, uma das primeiras ações do Ministério da Saúde-MS, que tinha como objetivo a valorização da família, foi a criação do Programa dos Agentes Comunitários de Saúde - PACS, iniciado em 1991, visando à prevenção das doenças e à promoção da saúde, através da capacitação de um morador da própria área para realizar essa função (MIRANDA, 2004). Na opinião de Zanetti (2000), esse programa foi o respon- sável pelo aumento da humanização da prática assistencial com a recuperação da atenção à população.

Segundo Conill (2002), de acordo com o Ministério da Saúde-MS, seria um equívoco considerar o PSF uma política para pobres pela utilização de baixa tecnologia. Já Gerschman (2001) cita que essas mudanças foram realmente uma maneira de cobrir assistencialmente os setores da população mais desassistidos, que são as pessoas que vivem em pobreza absoluta.

Segundo Brasil (2000), o PSF voltou-se para a atenção básica buscando a satisfação do usuário, através do estreito relacionamento dos profissionais de saúde com a comunidade, e estimulando-o ao reconhecimento da sua saúde como um direito de cidadania e, portanto, expressão de sua qualidade de vida.

Por ser o PSF um programa recente, há poucos estudos sobre a percepção que os usuários têm dos seus objetivos e sobre a satisfação desses com as ações realizadas pela equipe de saúde.

Para avaliar a satisfação com o programa, Trad et al. (2002) realizaram um estudo qualitativo com grupos de usuários, com características sócio-demográficas diferentes e grupos de profissionais do PSF em cinco municípios da Bahia, com pelo menos um ano de implementação. Os autores citam que o nível de satisfação dos usuários com o serviço de saúde envolve um ideal de serviço, uma noção de serviço merecido, uma idéia da experiência passada em situações de serviços similares e um nível subjetivo mínimo de qualidade de serviços a alcançar, para ser aceitável. Uma das conclusões, deste estudo refere-se às visitas dos agentes comunitários do PSF, tendo sido a demora o principal problema relatado por parte dos usuários do serviço. Segundo este estudo e o realizado por Pedrosa e Teles (2001), na cidade de Teresina-Piauí, os principais problemas do ponto de vista dos profissionais, que têm gerado insatisfação para os usuários do PSF, estão relacionados aos sistemas de referência (exames de alta complexidade e internações), que não asseguram continuidade do tratamento, por falta de estrutura. Conforme observação de Souza (2000), no que diz respeito à marcação das consultas tanto no programa, quanto no sistema de referência, têm havido problemas com os membros da equipe, em face do favorecimento de determinados grupos em detrimento de outros.

* Mestre em Saúde Bucal Coletiva - Professor da Universidade Luterana do Brasil - ULBRA - Curso de Odontologia ** Doutora em Saúde Pública - Professora da Universidade Federal do Rio Grande do Sul - Faculdade de Odontologia 
Conill (2002) realizou um estudo com vinte famílias, sendo dez famílias freqüentadoras e dez pouco freqüentadoras do PSF. A maior parte das pessoas que participaram da pesquisa eram mães, com primeiro grau incompleto. As famílias tinham renda de um a três salários mínimos e moravam na área há mais de dez anos. Esse estudo também observou a existência do problema de referência, como também a insatisfação dos usuários, pelo fato de que os profissionais da equipe de saúde tinham que atender a um número de famílias bem superior ao que preconizado pelo Ministério da Saúde. Um aspecto positivo apontado pelos usuários do programa foi a presença do agente comunitário, que facilita o acesso ao serviço de saúde.

Farias (2001) fez um estudo na região serrana do Rio de Janeiro, com residentes de dois bairros populares do município de Petrópolis, os quais tinham menos de doze anos de estudo e foram usuários do sistema público de saúde. Verificou qual era o motivo da adesão da população ao sistema de saúde privado e constatou que não apresentava nenhuma relação com a qualidade dos profissionais do sistema público de saúde, e, sim, com a dificuldade de acesso e a possibilidade de não conseguir atendimento num momento de urgência.

Esse mesmo autor ainda cita que as opiniões dos pacientes devem ter uma influência relevante na formulação de políticas de saúde para sucesso dos serviços, pois hoje ainda a organização destes está baseada no ponto de vista dos técnicos ao invés das necessidades e percepções da comunidade.

Entre os princípios do PSF, está o caráter substitutivo da prática convencional de assistência por um novo processo de trabalho, centrado na vigilância à saúde, com adoção da unidade da família como primeiro nível de ação do sistema. Além disso, o programa estabelece o direito à integralidade através da proteção, promoção e recuperação da saúde em diferentes níveis de atenção (primário, secundário e terciário) e ações intersetoriais (MARQUES; MENDES, 2002; PEDROSA; TELES, 2001).

Conforme descrito, os poucos estudos realizados indicam satisfação com a visita domiciliar dos agentes comunitários, que facilita o acesso ao serviço de saúde, mas, também, insatisfação com o sistema de referência, que não assegura continuidade do tratamento, e apreensão quanto a atendimento de urgência.

Estudos para verificar se os princípios do programa já estão sendo integralmente observados são importantes para as necessárias adaptações, buscando a satisfação do usuário.

Portanto, este estudo teve como objetivo descrever as opiniões dos moradores cadas- trados aos Programas Saúde da Família do bairro Lomba do Pinheiro da cidade de Porto Alegre - RS, da unidade de Saúde da Lomba, a respeito das seguintes questões:

1. satisfação com o serviço recebido;

2. experiência em situação de serviços semelhantes;

3. nível mínimo de qualidade de serviços a alcançar para ser considerado aceitável; e

4. conhecimento sobre o Conselho de Saúde e a importância da cidadania.

\section{MATERIAIS E MÉTODOS}

Esse trabalho foi um estudo qualitativo, que, como cita Triviños (1987), tem como característica ser essencialmente descritivo.

Conforme Porto Alegre (2003), o bairro Lomba do Pinheiro apresenta uma superfície de aproximadamente $15,22 \mathrm{~km}^{2}$, com uma população de aproximadamente 54.000 habitantes, conforme o censo realizado pelo IBGE em 2000. Jandrey (1999, p. 31), cita que:

"A área conhecida como Lomba do Pinheiro se distingue ao longo da Avenida João de Oliveira Remião, a qual está demarcada, em toda sua extensão, pelos pontos de paradas das linhas de ônibus, com vilarejos às margens direita e esquerda de cada "parada".

A autora ainda relata que a população é heterogênea, sendo que o contraste, se observa na presença de imóveis pertencentes às camadas de alto poder aquisitivo, e de um grande número de moradias precárias, do tipo barraco.

Atualmente, o bairro Lomba do Pinheiro apresenta seis unidades de Saúde com nove equipes do Programa Saúde da Família - PSF. Dentre essas, a unidade onde foi realizada a pesquisa que apresenta três equipes do PSF. Cada equipe é constituída por um médico, um enfermeiro, dois auxiliares de enfermagem e quatro agentes comunitários e está localizada na parada 12 da avenida João de Oliveira Remião. Desde 2002, junto a essas atuam duas Equipes de Saúde Bucal-ESB, com duas cirurgiãs-dentistas, duas auxiliares de consultório odontológico, e dois técnicos em higiene dental. Conforme a Portaria $n^{0} 267$, de 06 de março de 2001, essas equipes são da modalidade tipo 2 (BRASIL, 2001).

Em 2003, de acordo com as informações da Coordenadora do Programa Saúde da Família e dos agentes comunitários de saúde, encontravam - se cadastradas 2427 famílias, vinculadas às 3 equipes da unidade.

\section{PROJETO PILOTO}

Para a avaliação da metodologia que seria utilizada na pesquisa foi realizado em Março de 2004 um projeto piloto. Para tanto, escolheu-se intencionalmente um repre- sentante dos moradores cadastrados no PSF para a aplicação da entrevista do estudo. Também durante o projeto piloto, buscou-se conhecer os motivos que levaram as famílias a recusar o cadastro que foi feito no início do Programa. No entanto, nenhuma família procurada quis participar e esse grupo foi excluído da pesquisa.

\section{AMOSTRA DO ESTUDO}

A amostra do estudo foi do tipo intencional, que conforme Triviños (1987), deve incluir os indivíduos essenciais ao esclarecimento do assunto. Portanto, para representar os moradores cadastrados da Unidade do Programa Saúde da Família do bairro Lomba do Pinheiro de Porto Alegre - RS, foram sorteados inicialmente seis agentes comunitários, e de cada um destes, uma família foi sorteada através da tabela de números aleatórios. O responsável (mulher ou homem) de cada família sorteada, presente no domicilio no momento da visita, foi entrevistado.

Minayo (1996) cita que, no estudo qualitativo, a preocupação é com o aprofundamento e abrangência do tema que se está estudando, portanto, o critério do tamanho da amostra não é numérico; será suficiente quando houver compreensão dos padrões e das relações do que se está investigando, o que é também citado por Breilh (1995).

Como não houve alterações nas perguntas da entrevista do projeto piloto, este foi incluído na amostra final do estudo. Portanto, a amostra final do estudo foi composta por sete moradores cadastrados no PSF.

\section{MÉTODO DE COLETA DOS DA- DOS}

A avaliação consistiu de entrevistas semiestruturadas, com um roteiro pré-elaborado de perguntas abertas, para entender a realidade do Programa Saúde da Família. Segundo Minayo (1996), esse tipo de entrevista tem como qualidade esclarecer de forma mais abrangente possível as questões que se quer abordar no campo de estudo, e conforme Denker e Via (2001), tem a vantagem da flexibilidade, pois permite ao entrevistado dar informações mais complexas, emotivas ou mesmo comprovar os sentimentos que estão subjacentes a uma opinião.

Para cada participante da pesquisa foi questionado como aconteceu o contato inicial com o Programa Saúde da Família, citando os aspectos positivos e negativos em relação à visita domiciliar, ao relacionamento com a equipe de saúde e se esse serviço de saúde prestado pelo programa é de melhor qualidade e traz mais satisfação que o serviço que o anteriormente prestado a essa população.

Também foi questionado o que ele pensa em relação à necessidade de um serviço especializado de saúde, que não é oferecido pelo programa e se algum profissional de 
saúde já havia conversado sobre cidadania e sobre o Conselho de Saúde.

Para os moradores cadastrados no programa foi questionado se o que eles entendem por satisfação refere-se ao nível de conforto que eles sentem ao utilizar o serviço e à maneira como este alcança os seus objetivos (SANTOS, 2004)

Também foi verificado se a satisfação dos moradores cadastrados estava relacionada com: o nível de participação nas tomadas de decisões; recompensas (materiais e / ou simbólicas); a comparação com os outros serviços ou indivíduos (eqüidade) e as suas relações sociais dentro da comunidade (RODRIGUES, 2004).

Para a avaliação da percepção dos moradores cadastrados, foi considerada a descrição das experiências anteriores dos participantes em relação aos serviços de saúde, considerando os elementos da memória, do raciocínio, do juízo e do afeto, portanto, li- gando as qualidades objetivas dos sentidos a outros elementos subjetivos próprios de cada indivíduo (BELONE, 2003).

As entrevistas foram gravadas e depois transcritas. Objetivou-se com isto, captar as informações com a maior precisão possível. Essas entrevistas e a transcrição foram realizadas pelo próprio pesquisador

\section{MÉTODO DE ANÁLISE DOS DA- DOS}

Após a coleta dos dados, esses foram analisados, seguindo os passos de análise de pesquisa qualitativa proposta por Minayo (1996), de forma a interpretar e compreender o significado da percepção dos indivíduos estudados. Ela cita que essa análise leva o pesquisador a entender o texto, a fala, o depoimento, como resultado de um processo social e de conhecimento, frutos de múltiplas determinações e com significados específicos.

\section{CONSIDERAÇÕES ÉTICAS}

Todos os participantes da pesquisa foram informados da importância do estudo e da sua participação, tendo acesso a todas as informações sobre o trabalho, e que poderiam a qualquer momento desistir da pesquisa sem nenhum prejuízo pessoal. Todos assinaram o Consentimento Informado, conforme a Resolução 196/96, sobre pesquisas que envolvam seres humanos.

Esse trabalho foi submetido aos comitês de ética da Secretaria de Saúde, da cidade de Porto Alegre-RS, e, também, da Faculdade de Odontologia - UFRGS.

\section{RESULTADOS E DISCUSSÃO}

A partir do quadro com transcrição das principais falas obtidas nas entrevistas, realizadas com os moradores cadastrados, alguns conteúdos serão discutidos.

Figura 1 - Principais relatos dos moradores cadastrados na Unidade de Saúde da Lomba - PSF Lomba do Pinheiro, do bairro Lomba do Pinheiro na cidade de Porto Alegre -RS. Porto Alegre - RS, 2004.

\begin{tabular}{|c|c|c|c|c|c|c|c|}
\hline & Morador 1 & Morador 2 & Morador 3 & Morador 4 & Morador 5 & Morador 6 & Morador 7 \\
\hline $\begin{array}{l}\text { Como foi o } \\
\text { contato inicial } \\
\text { com o Progra- } \\
\text { ma saúde da } \\
\text { família? }\end{array}$ & $\begin{array}{l}\text { "Eles foram lá e } \\
\text { cadastraram o } \\
\text { pessoal da casa e } \\
\text { depois trocaram } \\
\text { as carteirinhas, } \\
\text { pois éramos } \\
\text { atendidos em ou- } \\
\text { tro posto do bair- } \\
\text { ro (parada 13)". }\end{array}$ & $\begin{array}{l}\text { "Antes de abrir } \\
\text { o programa eles } \\
\text { vieram aqui e } \\
\text { perguntaram se } \\
\text { a gente queria } \\
\text { participar". } \\
\text { Mora no bairro } \\
\text { faz } 2 \text { anos. }\end{array}$ & $\begin{array}{l}\text { Desde que abriu } \\
\text { o posto foram } \\
\text { cadastrados. Mora } \\
\text { no bairro faz } 23 \\
\text { a } 24 \text { anos. }\end{array}$ & $\begin{array}{l}\text { Vieram inicial- } \\
\text { mente fazer o } \\
\text { cadastro e de- } \\
\text { pois as visitas. } \\
\text { Mora no bairro } \\
\text { faz } 30 \text { anos. }\end{array}$ & $\begin{array}{l}\text { "Andavam nas } \\
\text { casas inscreven- } \\
\text { do as pessoas } \\
\text { antes do posto } \\
\text { abrir". Mora no } \\
\text { bairro há } 20 \\
\text { anos. }\end{array}$ & $\begin{array}{l}\text { Vieram na casa } \\
\text { e fizeram o ca- } \\
\text { dastro. Mora há } \\
28 \text { anos no bair- } \\
\text { ro }\end{array}$ & $\begin{array}{l}\text { "Vieram na casa } \\
\text { e pergunta ram } \\
\text { se queriam par- } \\
\text { ticipar". Mora } \\
\text { no bairro. Faz } 2 \\
\text { anos }\end{array}$ \\
\hline $\begin{array}{l}\text { Como vê a sua } \\
\text { saúde? }\end{array}$ & $\begin{array}{l}\text { "Considera boa, } \\
\text { pois não tem } \\
\text { doença". }\end{array}$ & $\begin{array}{l}\text { "Considera mui- } \\
\text { to boa, pois faz } \\
\text { exames e não } \\
\text { tem nada". }\end{array}$ & $\begin{array}{l}\text { "Teve alguns } \\
\text { problemas de } \\
\text { saúde, mas está } \\
\text { controlado, e } \\
\text { por isso conside- } \\
\text { ra ótima". }\end{array}$ & $\begin{array}{l}\text { "Considera bem } \\
\text { melhor, princi- } \\
\text { palmente por- } \\
\text { que agora real- } \\
\text { mente tem aten- } \\
\text { dimento". }\end{array}$ & $\begin{array}{l}\text { "Tá com a dia- } \\
\text { bete controlada } \\
\text { e por isso não } \\
\text { tem problema } \\
\text { de saúde". }\end{array}$ & $\begin{array}{l}\text { "Considera boa, a } \\
\text { mesma coisa que } \\
\text { tinha antes do pro- } \\
\text { grama". "A única } \\
\text { coisa que mudou } \\
\text { foi o acesso ao } \\
\text { dentista". }\end{array}$ & $\begin{array}{l}\text { "Se sente bem, } \\
\text { nunca teve um } \\
\text { problema sério } \\
\text { de saúde". }\end{array}$ \\
\hline $\begin{array}{l}\text { Como era o } \\
\text { serviço de saú- } \\
\text { de que tinha } \\
\text { anteriormente } \\
\text { e o que tem } \\
\text { agora? }\end{array}$ & $\begin{array}{l}\text { O serviço que ti- } \\
\text { nha anterior- } \\
\text { mente era parti- } \\
\text { cular "Policlíni- } \\
\text { ca". "O que } \\
\text { tem agora é } \\
\text { muito bom, só } \\
\text { que médico par- } \\
\text { ticular é muito } \\
\text { melhor do que } \\
\text { do posto, não } \\
\text { que os do posto } \\
\text { não atendam } \\
\text { bem, o ruimé fi- } \\
\text { car nas filas". }\end{array}$ & $\begin{array}{l}\text { Usava um posto } \\
\text { de saúde (UBS). } \\
\text { "Acha que o ser- } \\
\text { viço de hoje é a } \\
\text { mesma coisa } \\
\text { que tinha antes. } \\
\text { A única vanta- } \\
\text { gem são as visi- } \\
\text { tas, pois tem um } \\
\text { pai que não ca- } \\
\text { minha". Consi- } \\
\text { dera todos os } \\
\text { postos de saúde } \\
\text { iguais, pois tem } \\
\text { que pegar fila, só } \\
\text { que agora pode } \\
\text { ir mais tarde } \\
\text { para a fila. }\end{array}$ & $\begin{array}{l}\text { Nunca freqüen- } \\
\text { tou um outro } \\
\text { serviço de saú- } \\
\text { de. "Considera } \\
\text { o serviço ótimo, } \\
\text { mesmo às vezes } \\
\text { faltando algum } \\
\text { medicamento". }\end{array}$ & $\begin{array}{l}\text { "Tinha serviço } \\
\text { particular que } \\
\text { acha que é do } \\
\text { mesmo nível } \\
\text { que tem agora. } \\
\text { A única vanta- } \\
\text { gem do particu- } \\
\text { lar é que não ti- } \\
\text { nha fila". }\end{array}$ & $\begin{array}{l}\text { “Agora está } \\
\text { muito melhor o } \\
\text { atendimento, } \\
\text { pois é mais fácil } \\
\text { ter acesso ao } \\
\text { serviço. Não } \\
\text { tem que ir para } \\
\text { fila as } 4 \text { ou às } 5 \\
\text { horas da ma- } \\
\text { nhã". }\end{array}$ & $\begin{array}{l}\text { "Considera me- } \\
\text { lhor, porque } \\
\text { consegue mais } \\
\text { consulta por es- } \\
\text { tar perto da sua } \\
\text { casa, não pela } \\
\text { qualidade do } \\
\text { serviço"."Acha } \\
\text { que os profissi- } \\
\text { onais são atenci- } \\
\text { osos, sendo } \\
\text { igual ao serviço } \\
\text { que tinha antes, } \\
\text { que também era } \\
\text { do SUS". }\end{array}$ & $\begin{array}{l}\text { Acha que me- } \\
\text { lhorou bastante } \\
\text { mesmo quando } \\
\text { comparado com } \\
\text { o serviço priva- } \\
\text { do que tinha } \\
\text { antes do PSF. } \\
\text { "Ele é melhor, } \\
\text { pois tem um } \\
\text { contato humano } \\
\text { no atendimen to } \\
\text { e não precisa ir } \\
\text { para filas enor- } \\
\text { mes". }\end{array}$ \\
\hline
\end{tabular}




\begin{tabular}{|c|c|c|c|c|c|c|c|}
\hline & Morador 1 & Morador 2 & Morador 3 & Morador 4 & Morador 5 & Morador 6 & Morador 7 \\
\hline $\begin{array}{l}\text { Como é o ser- } \\
\text { viço especi- } \\
\text { alizado de saú- } \\
\text { de? }\end{array}$ & $\begin{array}{l}\text { "Cita que é di- } \\
\text { fícil., um médi- } \\
\text { co para trocar os } \\
\text { óculos demora } \\
\text { mais de um } \\
\text { ano.Acha que } \\
\text { não é culpa do } \\
\text { posto é mais à } \\
\text { frente". }\end{array}$ & $\begin{array}{l}\text { "Demora muito } \\
\text { para conseguir } \\
\text { uma consulta } \\
\text { (mais de seis } \\
\text { meses para um } \\
\text { oftalmo), não } \\
\text { sabe de quem é } \\
\text { a culpa da de- } \\
\text { mora, contudo } \\
\text { acredita que } \\
\text { não é do pesso- } \\
\text { al do PSF". }\end{array}$ & $\begin{array}{l}\text { "Apenas acha } \\
\text { que demora, } \\
\text { pois nunca pre- } \\
\text { cisou. Acredita } \\
\text { que essa demo- } \\
\text { ra não é do pes- } \\
\text { soal do posto e } \\
\text { sim do departa- } \\
\text { mento do hospi- } \\
\text { tal". }\end{array}$ & $\begin{array}{l}\text { "Precisou e foi } \\
\text { bem rápido. Só } \\
\text { que acha que se } \\
\text { precisar de ou- } \\
\text { tras consultas } \\
\text { pode demorar. } \\
\text { Acha que quem } \\
\text { escolhe a ordem } \\
\text { do atendimento } \\
\text { é o profissional, } \\
\text { levando em con- } \\
\text { ta a gravidade } \\
\text { do caso. E o } \\
\text { problema da } \\
\text { demora é por- } \\
\text { que tem muita } \\
\text { gente precisan- } \\
\text { do". }\end{array}$ & $\begin{array}{l}\text { "Não precisou e } \\
\text { não sabe se de- } \\
\text { mora para con- } \\
\text { seguir uma con- } \\
\text { sulta". }\end{array}$ & $\begin{array}{l}\text { "Demora muito, } \\
\text { às vezes um ano. } \\
\text { Acha que essa } \\
\text { demora não é } \\
\text { problema do } \\
\text { posto, só que não } \\
\text { sabe quem é o } \\
\text { responsável". }\end{array}$ & $\begin{array}{l}\text { "Precisou de } \\
\text { um serviço espe- } \\
\text { cializado, mas } \\
\text { foi fácil, pois es- } \\
\text { tava no período } \\
\text { de gravidez. } \\
\text { Mas acha que } \\
\text { existem muitos } \\
\text { casos bem difí- } \\
\text { ceis dependen } \\
\text { do da especiali- } \\
\text { dade. Acha que } \\
\text { o problema é de } \\
\text { outras pessoas e } \\
\text { não do PSF". }\end{array}$ \\
\hline $\begin{array}{l}\text { Como é o seu- } \\
\text { relacionamen- } \\
\text { to com a equi- } \\
\text { pe de saúde? }\end{array}$ & $\begin{array}{l}\text { "Foi muito bem } \\
\text { tratado por toda } \\
\text { equipe". }\end{array}$ & $\begin{array}{l}\text { "Sempre foi } \\
\text { bem tratado } \\
\text { nesse programa } \\
\text { e nos outros } \\
\text { também". }\end{array}$ & $\begin{array}{l}\text { "Sempre foi } \\
\text { bem atendido } \\
\text { por toda a equi- } \\
\text { pe". }\end{array}$ & $\begin{array}{l}\text { "Tenho um bom } \\
\text { relacionamento, } \\
\text { me tratam bem } \\
\text { e eu trato eles } \\
\text { bem". }\end{array}$ & $\begin{array}{l}\text { "Agora é bem } \\
\text { melhor do que } \\
\text { eu tinha antes } \\
\text { no outro servi- } \\
\text { ço". }\end{array}$ & $\begin{array}{l}\text { "Acha que eles } \\
\text { tratam bem. } \\
\text { Apenas uma } \\
\text { vez foi mal aten- } \\
\text { dida por um } \\
\text { membro da } \\
\text { equipe". }\end{array}$ & $\begin{array}{l}\text { Não respondeu } \\
\text { a essa questão }\end{array}$ \\
\hline $\begin{array}{l}\text { O que você } \\
\text { acha da visita } \\
\text { da agente co- } \\
\text { munitária de } \\
\text { saúde? }\end{array}$ & $\begin{array}{l}\text { "Acha bom e } \\
\text { não se sente in- } \\
\text { vadida na sua } \\
\text { privacidade". }\end{array}$ & $\begin{array}{l}\text { "Acha impor- } \\
\text { tante porque } \\
\text { eles vêm ver } \\
\text { como está a si- } \\
\text { tuação. E não se } \\
\text { sente invadida, } \\
\text { por ter uma pes- } \\
\text { soa indo a sua } \\
\text { casa". }\end{array}$ & $\begin{array}{l}\text { "Acha muito } \\
\text { bom ter a visita } \\
\text { e não sente a } \\
\text { sua privacidade } \\
\text { invadida". }\end{array}$ & $\begin{array}{l}\text { "Acha muito } \\
\text { bom esse inte- } \\
\text { resse da agente } \\
\text { pela sua saúde. } \\
\text { Não sente a sua } \\
\text { privacidade in- } \\
\text { vadida em ne- } \\
\text { nhum momen- } \\
\text { to". }\end{array}$ & $\begin{array}{l}\text { "Acha super } \\
\text { bom de as pes- } \\
\text { soas ir lá, falar } \\
\text { e orientar quan- } \\
\text { to aos remédios } \\
\text { que tem que to- } \\
\text { mar" }\end{array}$ & $\begin{array}{l}\text { "Acha normal, } \\
\text { pois é o traba- } \\
\text { lho delas. Não } \\
\text { se sente invadi- } \\
\text { da em nenhum } \\
\text { mo m e n to". } \\
\text { Ain da citou } \\
\text { que a agente } \\
\text { não está orien- } \\
\text { tando as pesso- } \\
\text { as sobre alguns } \\
\text { proble mas de } \\
\text { saúde. }\end{array}$ & $\begin{array}{l}\text { "Acha bom, } \\
\text { pois eles conse- } \\
\text { guem saber } \\
\text { mais sobre as } \\
\text { necessida des } \\
\text { da família. Não } \\
\text { se sente invadi- } \\
\text { da pela visita" }\end{array}$ \\
\hline $\begin{array}{l}\text { Algum profis- } \\
\text { sional já con- } \\
\text { versou sobre } \\
\text { cidadania? }\end{array}$ & $\begin{array}{l}\text { "Nunca nin- } \\
\text { guém falou } \\
\text { nada. Não acha } \\
\text { importante sa- } \\
\text { ber sobre os } \\
\text { seus direitos". }\end{array}$ & $\begin{array}{l}\text { "Nunca nin- } \\
\text { guém falou } \\
\text { nada. Acha im- } \\
\text { portante saber } \\
\text { sobre os seus } \\
\text { direitos". }\end{array}$ & $\begin{array}{l}\text { "Nunca conver- } \\
\text { saram nada, } \\
\text { apenas sobre } \\
\text { atendimento". }\end{array}$ & $\begin{array}{l}\text { "Nunca conver- } \\
\text { saram nada, } \\
\text { apenas da me- } \\
\text { lhoria do posto". }\end{array}$ & $\begin{array}{l}\text { "Nunca falaram } \\
\text { nada., apenas } \\
\text { os locais onde } \\
\text { existem medica- } \\
\text { mentos ou exa- } \\
\text { mes". }\end{array}$ & $\begin{array}{l}\text { "Nunca nada. A } \\
\text { única coisa foi } \\
\text { trazer o dia da } \\
\text { consulta". }\end{array}$ & $\begin{array}{l}\text { "Não, nunca fa- } \\
\text { laram nada". }\end{array}$ \\
\hline $\begin{array}{l}\text { Alguém já fa- } \\
\text { lou sobre o } \\
\text { Conselho de } \\
\text { Saúde? }\end{array}$ & $\begin{array}{l}\text { “Não sabe o que } \\
\text { é Conselho de } \\
\text { Saúde e nunca } \\
\text { ninguém disse } \\
\text { nada”. }\end{array}$ & $\begin{array}{l}\text { "Não sabe o que } \\
\text { é o Conselho de } \\
\text { Saúde e nunca } \\
\text { ninguém disse } \\
\text { nada sobre o } \\
\text { Conselho. Até } \\
\text { gostaria de par- } \\
\text { ticipar". }\end{array}$ & $\begin{array}{l}\text { "Nunca nin- } \\
\text { guém falou } \\
\text { nada, apenas li } \\
\text { alguma coisa no } \\
\text { posto". }\end{array}$ & $\begin{array}{l}\text { "Nunca nin- } \\
\text { guém falou nada } \\
\text { sobre o Conse- } \\
\text { lho de Saúde". }\end{array}$ & $\begin{array}{l}\text { "Nunca falaram } \\
\text { nada., apenas } \\
\text { das reuniões na } \\
\text { creche sobre } \\
\text { saúde". }\end{array}$ & $\begin{array}{l}\text { "Nunca nin- } \\
\text { guém falou } \\
\text { nada". A mãe } \\
\text { comentou que a } \\
\text { agente uma vez } \\
\text { trouxe informa- } \\
\text { ção sobre uma } \\
\text { reunião. }\end{array}$ & $\begin{array}{l}\text { "Nunca falaram } \\
\text { nada, contudo } \\
\text { já li uma vez no } \\
\text { postinho sobre a } \\
\text { reunião no Con- } \\
\text { selho". }\end{array}$ \\
\hline
\end{tabular}


Contato inicial com a população quando da implementação do PSF

$O$ primeiro contato com o PSF para a maioria dos moradores ocorreu por visita dos profissionais ao domicílio antes da abertura do programa no bairro para realizar o cadastramento das famílias, como descreve o morador 6:

"Eles vieram aqui fazer o cadastro das pessoas que moravam na casa! Em cada casa! E aí, fizeram o cadastro de cada família e levaram para o posto e depois viria a carteirinha".

Levy, Matos e Tomita (2004), quando da implementação do Programa dos Agentes Comunitários de Saúde (PACS), no município de Bauru - SP, em 2000, observaram que o primeiro contato da população se deu através do cadastramento das famílias e, posteriormente, iniciaram-se as orientações para os grupos de risco.

O cadastramento realizado pela equipe quando da implementação do programa tem que ser constantemente monitorado pelo fato de que muitas famílias acabam migrando para outros bairros ou cidades vizinhas devido a problemas socioeconômicos. Cabe à equipe multiprofissional realizar a verificação da presença de novas famílias e fazer um novo cadastramento. No entanto, essas novas famílias frequientemente não conseguem cadastro pelo fato da existência de excesso de famílias naquela área. Sequer durante o cadastramento inicial são cadastradas todas as famílias existentes, pois o número máximo de duzentos e cinqüenta que cada agente pode atender, não é suficiente para suprir as necessidades daquela microárea. Neste estudo apenas duas famílias das sete entrevistadas foram cadastradas após a territorialização inicial realizada pela equipe; o restante das famílias estava desde o início do programa.

Como os moradores cadastrados no PSF consideram a sua saúde

Todos os moradores cadastrados relataram que consideram a sua saúde boa, sempre citando na questão da ausência de doenças, de acordo com a fala do morador 2 :

".....Muito boa, eu acho!....... Porque eu procuro o médico, faço os exames e os exames dão bom!".

Essa parece ser uma percepção muito difundida na população, pois Lopes e Almeida (2001), que em uma pesquisa realizada com cento e oitenta e três membros do Conselho de Saúde da cidade de Londrina - PR, verificaram que $1 / 4$ destes acreditam que a saúde é apenas ausência de sintomas da do- ença, evidenciando a idéia de que mais médicos, remédios e serviços abertos vinte e quatro horas resolveriam os problemas de saúde.

A idéia da saúde relacionada apenas ao aumento do número de médicos e de hospitais deve-se ao medo da população de, num momento de urgência, não encontrar atendimento, e por entender que a doença está relacionada a apenas aspectos biológicos. Só ocorrerá uma mudança com o aumento da participação nas discussões dos problemas de saúde do seu bairro e entender que a saúde é o resultado da possibilidade de usufruir de diversas condições como saneamento, habitação, educação, lazer etc. A partir disso, poderá reconhecer que essas mudanças são importantes para melhorar a sua qualidade de vida. No entanto, isso não tem ocorrido em relação à população adscrita às três equipes de PSF da Unidade de Saúde da Lomba, pois os moradores não reconhecem quem são os representantes (líderes) e quais são os locais (Conselhos e associações de bairros etc..) que podem procurar para melhorar as suas condições de vida.

O morador 4 relatou que considera a sua saúde boa porque agora realmente tem bom atendimento. Ele disse:

"Melhorou em tudo! Porque a gente tem atendimento, né! Tem acolhimento com a enfermeira.......".

Já para outro morador (6), o aspecto que mudou e contribuiu para melhorar a sua saúde foi o acesso ao dentista, como se pode ver na sua fala:

"Não, a parte do dentista tá melhor! Porque antes era muito difícil conseguir o dentista! Muito difícil! A gente (agora) já tem consultas agendadas! E...... só é avisado pelo agente comunitário, né, a gente vai lá. Na parte do dentista tá ótimo!"

A satisfação da população em relação ao acolhimento também foi relatada no estudo de Schimith e Lima (2004), que citam o acolhimento como um meio que possibilita regular o acesso a ações e a serviços mais adequados, contribuindo para satisfação do usuário. O aumento do acesso a consulta odontológica deve-se a que, entre 2002 e 2005 , foram implementadas mais de oito mil Equipes de Saúde Bucal-ESB para atuar junto às equipes do PSF.(BRASIL, 2005) Mas, apesar do aumento dos incentivos do Ministério da Saúde-MS, em 2005 ainda há mais de vinte e sete milhões de pessoas que nunca foram ao dentista. Portanto, mesmo com os investimentos financeiros no setor, ainda $15,9 \%$ da população não têm acesso ao dentista (CONSELHO FEDERAL DE ODONTO-
LOGIA, 2005). Cabe ao MS verificar se os programas que estão sendo implementados realmente contemplam as áreas que necessitam de mais serviços de saúde, pois os dados do MS de Maio de 2005, em relação à saúde bucal mostram que os estados de Minas Gerais, Paraíba, Ceará e Bahia têm o maior número de ESB do Brasil, com um total de 3619 ou $31 \%$ equipes existentes. No entanto, estes estados têm apenas 25\% da população do Brasil.

A implementação da ESB e do PSF depende da aceitação dos gestores municipais, pois o MS e os estados só dão incentivos para os municípios, cabendo a estes o pagamento dos recursos humanos e da infra-estrutura. Muitas vezes isto acaba comprometendo o orçamento do município que, por este motivo, não oferece esses serviços.

Qualidade do serviço prestado no PSF e encaminhamento para serviços de média e alta complexidade

Comparando o serviço que é prestado pelo Programa Saúde da Família com outros prestados aos moradores em algum momento das suas vidas (dois usavam serviço privado, quatro serviço público e um não fazia uso de qualquer outro tipo de serviço), foi relatado que o atual está bom, ou até melhor, e isso se dá principalmente, pelo fato de conseguir mais acesso e sem a necessidade de madrugar nas filas à porta da unidade de saúde. $\mathrm{O}$ morador 4 , assim se expressou:

"Eu creio que é o mesmo nível! O particular a única comodidade que tinha, eu só ligava e ia, né! Só marcava e ia! Aqui eu tenho que ir para a fila para pegar ficha, mas mesmo assim, eu creio que o atendimento médico é a mesma coisa".

Também foi relatado por um dos moradores que o que melhorou em relação ao serviço anterior foi o fato de agora existir um contato humano durante o atendimento. Isso também foi comentado por Zanetti (2000), quando descreve que esse programa foi o responsável pelo aumento da humanização da prática assistencial com a recuperação da atenção à população.

A questão da qualidade dos serviços de saúde ainda está muito ligada ao acesso, ou seja, ".....se tenho que ficar na fila" e ".....se vou conseguir ou não a consulta", o que também foi observado no trabalho de Trad et al (2002), realizado na Bahia com profissionais e usuários do PSF.

Segundo Donabediam (1998), a avaliação dos serviços de saúde envolve a estrutura, o processo e os resultados. No caso da avaliação dos moradores cadastrados do PSF, a estrutura e o processo foram citados como causa do aumento do acesso ao serviço e 
implementação do acolhimento. As mudanças dos resultados só serão visíveis no futuro, com a realização de pesquisas que revelarão a mudança de comportamento e conhecimento da população em relação à saúde.

A satisfação observada pela comunidade em relação ao serviço de saúde decorre principalmente porque boa parte da população tinha pouco ou quase nenhum acesso a esse tipo de atendimento e, nesse primeiro momento a diminuição das filas acaba sendo um fator de extrema importância.

No entanto, em alguns locais estas mudanças ainda não são perceptíveis. Schimith e Lima (2004), avaliando acolhimento e vínculo em um PSF da $4^{\mathrm{a}}$ Regional de Saúde do Rio Grande do Sul, citam que a estratégia do PSF ainda continua mantendo a forma excludente de atendimento, no qual a prioridade é de quem chega primeiro, com a população sendo desumanamente tratada, tendo que enfrentar a fila de madrugada. Já Farias (2001), que realizou um estudo na região serrana do Rio de Janeiro com usuários do sistema público de saúde, verificou que a causa pela qual as pessoas procuram o serviço privado é o medo de não conseguir um atendimento num momento de urgência e não a falta de qualidade dos profissionais que atuam no serviço público.

Na questão de como os moradores cadastrados observam o serviço especializado, três deles relataram que demora muito para conseguir uma consulta, como na fala do morador 2:

"Demora muito! Quando eles não conseguem encaixar a gente no lugar de alguém que desista sabe, aí demora!".

Dois moradores relataram que ainda não precisaram do serviço especializado, mas acham que será difícil conseguir uma consulta se necessitarem. Outros dois disseram que precisaram, e conseguiram rapidamente, mas acreditam que, em algum outro momento, poderão ter dificuldades. A dificuldade de conseguir serviços especializados foi observada nos estudos de Santos et al (2000) em Acari - RN, de Pedrosa e Teles (2001), na cidade de Teresina - Piauí, de Conill (2002), na cidade de Florianópolis e de Schimith e Lima (2004) em um município da $4^{\text {a }}$ Regional de Saúde do Rio Grande do Sul RS.

A grande dificuldade da resolução dos problemas de saúde média e alta complexidade deve-se principalmente à falta de recursos financeiros para a contratação de profissionais especializados. Pela Emenda Constitucional 29, de 2000, 30\% dos recursos da seguridade social e $10 \%$ dos impostos arrecadados investidos deverão ser aplica- dos pelo Governo Federal em saúde. Estes valores dependem da variação do Produto Interno Bruto - PIB, e acabam não sendo suficientes para a contratação de recursos humanos e para criação e manutenção de centros destinados ao atendimento das necessidades de média e alta complexidade, que exigem alta tecnologia. Em relação aos Estados, estes têm que aplicar $12 \%$ da sua arrecadação, e os municípios deverão gastar, em saúde, no mínimo $15 \%$ da receita resultante de impostos. Muitas vezes as prefeituras não investem mais do que os $15 \%$, pois pela lei de Responsabilidade Fiscal (Lei Complementar 101), os gastos com a contratação de recursos humanos não podem ultrapassar $60 \%$ do orçamento do município.

\section{Relacionamento com a equipe de saúde do PSF e a visita domiciliar}

No que se refere ao relacionamento com a equipe multiprofissional, todos os moradores cadastrados disseram que este é bom. Apenas um morador citou que foi mal atendido uma vez na unidade de saúde.

Em relação à visita domiciliar, todos os usuários disseram que acham importante a visita realizada pelo agente comunitário de saúde, como na fala do morador7:

"........... consegue saber mais o que se passa, né! Quais as necessidades de cada família, que problema tem, né! Se ela tem uma urgência maior ou menor em termos de atendimento........".

Conill (2002), na cidade de Florianópolis - SC, cita também como aspecto positivo as visitas dos agentes comunitários de saúde, que facilitam o acesso aos serviços de saúde.

Nenhum dos moradores demonstrou sentir-se invadido na sua privacidade pelo profissional de saúde que realiza a visita domiciliar. Já isto parece acontecer com os moradores que não tinham cadastro no programa. Durante o projeto piloto, as famílias não cadastradas, que foram procuradas para participar da pesquisa e não aceitaram, disseram que não queriam assistência do PSF porque tinham plano privado. Mas é possível que a invasão da privacidade tenha sido a verdadeira razão pela qual estas famílias não queriam participar do PSF, como foi relatado pelos próprios agentes comunitários, quando perguntados sobre essas famílias. Eles teriam sido considerados por essas "invasores de sua privacidade".

Participação no Conselho de Saúde e cidadania

Conhecer como encaminhar as sugestões para melhorar a qualidade dos serviços a elas prestados e, conseqüentemente, a sua quali- dade de vida é de extrema importância para a população. Dentro desta perspectiva foi perguntado se algum profissional tinha conversado sobre a questão da cidadania com os moradores. Todos disseram que nunca foi dito nada sobre cidadania.

Dois moradores relataram que os profissionais apenas conversam sobre saúde e os locais onde eles podem conseguir medicamentos, como na fala do morador 3 :

"Não sobre isso aí......[Conselhos e Cidadanial, sobre isso aí não! Só atendimento lá dentro que eu tive......".

Conforme estudo de Gerschman (2004), com os representantes do Conselho de Saúde este é um espaço em que ocorre a efetivação da cidadania, pois, segundo Gonçalves e Almeida (2002), o controle social é um componente essencial para o seu exercício.

No que se refere ao Conselho de Saúde, os moradores cadastrados afirmavam desconhecê-lo, pois nenhum profissional falou de que forma eles poderiam participar das reuniões do referido Conselho. Apenas dois moradores relataram que já tinham lido um cartaz que convidava para uma reunião do Conselho na unidade de saúde, como pode ser observado na fala do morador 7 :

"Eu sei porque eu li lá no postinho um dia, lá! Tal dia da reunião..., não sei o que....., com a doutora tal..., em tal horário, no Conselho de Saúde".

Gerschman (2004) também observou que a população participa muito pouco das reuniões do Conselho de Saúde, enquanto Lopes e Almeida (2004) verificaram em seu estudo com representantes do Conselho de Saúde de Londrina-PR, que esta é uma das atribuições que devem ser realizadas pelos conselheiros.

É necessário que os profissionais se qualifiquem, conhecendo melhor as diretrizes do Sistema Único de Saúde - SUS, e saibam responder às indagações feitas pela comunidade. Desta forma, poderia haver uma mudança da visão dos profissionais, que quando são indicados para representantes no Conselho de Saúde, consideram isso como "um presente de grego". Considerando importante a participação no Conselho, eles acabariam motivando-se, e conseqüentemente, informando à população que o Conselho de Saúde é um local de grande importância para a formulação e regulamentação das políticas de saúde.

É importante que a população saiba que a sua participação em espaços de discussão poderá permitir que o seu bairro e município tenham políticas de saúde que realmen- 
te contemplem as suas verdadeiras necessidades.

\section{CONSIDERAÇÕES FINAIS}

A partir do relato dos moradores cadastrados no Programa Saúde da Família do bairro Lomba do Pinheiro, observou-se que o primeiro contato da equipe de saúde com a população ocorreu quando da realização da territorialização, que é quando os profissionais estão conhecendo a área na qual atuarão e, também, identificando os grupos de risco.

Os moradores consideram que a qualidade dos serviços prestados pela equipe do PSF é tão boa ou mesmo melhor do que os outros serviços de saúde que eles já foram usuários. A única desvantagem em relação ao serviço privado é a necessidade de ir à unidade mais cedo para garantir uma ficha e conseguir uma consulta. Para tentar diminuir essa dificuldade, a implementação do acolhimento pela equipe do PSF tem sido relatada pelos moradores como um aspecto positivo, pois permite que ao procurar a unidade de saúde o seu problema seja resolvido ou encaminhado.

O sucesso da equipe multiprofissional no atendimento integral da população adscrita está relacionado principalmente ao fato da continuidade do atendimento iniciado na unidade básica de saúde. No entanto, os moradores relataram que, quando necessitam de um atendimento especializado, têm que esperar muito tempo para conseguir a consulta. Este fato gera intranqüilidade, pois até mesmo aqueles que nunca precisaram acreditam que encontrarão dificuldades.

A tentativa de aumentar os recursos financeiros e melhorar as políticas de saúde passa por uma participação efetiva da comunidade em espaços de discussão, como os Conselhos de Saúde. No entanto, neste estudo os moradores relataram que não recebem nenhuma informação de como podem participar das reuniões.

\section{ABSTRACT}

The present work was a qualitative research aimed to evaluate the satisfaction of the inhabitants enrolled at the Lomba Health Care Center, where the units of the Family Health Program - PSF of the Lomba do Pinheiro neighborhood in the city of Porto Alegre - RS provide services, in relation to the service provided by the health care staff comparing to those provided in any moment of their lives. Topics about their participation and their knowledge on the Health Council were also approached. Research data were collected by means of semi-structured interviews with open-ended questions. Seven inhabitants enrolled at the PSF were interviewed.
It was observed, by means of the interviews, that the service provided by the PSF staff was considered as very good when compared to the other services with which they have had contact before. The improvement of the service's quality was related to the shortening of the lines for access and to the presence of community workers, who follow up their health by means of house visits. These were never considered as an invasion of privacy. A topic that was considered as negative refers to the difficult access to medium and high complexity health services, what hinders the resolution of the community's health problems. The enrolled inhabitants consider their health as good. However, by the analysis of their answers, the fact of having a good health is related to the absence of disease symptoms. In relation to the Health Council, the enrolled inhabitants said that the health staff never said anything neither about its importance nor how people can participate of them.

\section{KEYWORDS:}

Qualitative Research. Health Service Research. Family Health Program

\section{REFERENCIAS}

BELLONE, G.J. Senso Percepção. Psicoweb 2003. Disponível em <www.psicoweb.med.br/ cursos/ percep.html > . Acesso em: 31 jan 2004.

BRASIL. Ministério da Saúde. Departamento de Atenção Básica / SAS. Relatório de Dados para Pagamento do Incentivo às Equipes de saúde Bucal. Brasília. Agosto, 2005.

BRASIL. Ministério da Saúde. 9 $9^{\mathrm{a}}$ Conferência Nacional de Saúde. Disponível em: < www. Fiocruz.br/ histconferencias $>$. Acesso em: 22 jan 2004.

BRASIL, Ministério da Saúde. Conselho Nacional de Saúde, Comissão Nacional de Etica em Pesquisa. Manual Operacional para Comitês de Ética em Pesquisa. Brasília, 2002.

BRASIL. Ministério da Saúde. Portaria 267 de 06 de março de 2001. Aprova as normas e diretrizes de inclusão da saúde bucal na estratégia do Programa de Saúde da Família (PSF). Diário Oficial da União, Brasília, DF, 07 de mar. 2001. Secção 1, pág 67.

BRASIL. Ministério da Saúde. Secretaria de Políticas de Saúde, Departamento de Atenção Básica.Programa Saúde da Família. Rev. Saúde Pública, São Paulo, v. 34, n. 3, p. 316-319, jun., 2000.
BREILH. J. Las Tecnicas Intensivas (Qualitativas) Em La Invetigacion En Salud: Debates Sobre Sus Usos y Distorsiones. In .Nuevos Conceptos y Técnicas de Investigación. 2ed. Quito: CEAS, 1995. Cap.4, p.107-145.

CONSELHO FEDERAL DE ODONTOLOGIA. Brasileiro ainda vai pouco ao Dentista. Jornal do CFO, Ano15, n.60, p.11, maio/jun., 2005.

CONILL, E. M. Políticas de Atenção Primária e Reformas Sanitárias: Discutindo Avaliação a partir de Análise do Programa Saúde da Família em Florianópolis, Santa Catarina, 1994-2000. Cad. Saúde Publ., Rio de Janeiro, v.18, supl., p.191-202, 2002.

DENCKER, A. F. M.; VIÁ, S. C. Técnicas de Entrevista e Questionário. In . Pesquisa Empírica em Ciências Humanas - com ênfase em comunicação. São Paulo: Futura, 2001. Cap. 13, p.155-167.

DONABEDIAN, A. The Quality of Care. JAMA, Chicago, v.260, no.12, p.17431748, Sept, 1998.

EC - 29. Casa Civil. Subchefia para Assuntos Jurídicos. Disponível em < https/ www.planalto.gov.br/ccivil_03/constituicao/emendas/EMC/Emc29. htm>, Acesso em: out. 2005.

FARIAS, L. O. Estratégias Individuais de Proteção à Saúde: Um Estudo da Adesão ao Sistema de Saúde Suplementar. Cienc. Saúde Col., Rio de Janeiro, v.6, n.2, p.405-416, 2001.

GERSCHMAN, S. Municipalização e Inovação Gerencial. Um balanço da Década de 1990. Cienc. Saúde Col., Rio de Janeiro, v.6, n.2, p.417-434, 2001.

GERSCHMAN, S. Conselhos Municipais de Saúde: Atuação e Representação das Comunidades Populares. Cad. Saúde Públ., Rio de Janeiro, v.20, n.6, p.16701681, nov./dez., 2004.

GONÇALVES, M.L; ALMEIDA, M. C. $\mathrm{P}$ de. Construindo o Controle Social e a Cidadania em uma Experiência Concreta: O Conselho Municipal de Saúde (CMS) de Ribeirão Preto (SP). Saúde Deb., Rio de Janeiro, v.26, n.61, p.167-175, maio/ ago., 2002

JANDREY, C. M. Absenteísmo no Atendimento Clínico-Odontológico: O caso do 
Módulo de Saúde Comunitária do CPOS. 1999.135f. Dissertação (Mestrado em Saúde Bucal Coletiva) - Universidade Federal do Rio Grande do Sul, Faculdade de Odontologia, Porto Alegre.

LEI COMPLEMENTAR 101. Casa Civil. Subchefia para Assuntos Jurídicos. Disponível em < www. Planalto.gov.br/ ccivil 03/leis/LCP/Lçp101.htm>. Acesso em: outubro de 2005.

LEVY, F.M; MATOS, P.E.S; TOMITA, E.T. Programa de Agentes Comunitários da Saúde: A Percepção de Usuários e Trabalhadores da Saúde. Cad. Saúde Públ., Rio de Janeiro v.20, n.1, p.197203, jan / fev, 2004.

LOPES, M.L.S; ALMEIDA, M,J de. Conselhos Locais de Saúde em Londrina (PR): Realidade e Desafios. Saúde Deb., Rio de Janeiro, v.25, n.59, p. 16-28, set./ dez., 2001.

MARQUES, R. M.; MENDES, A. A Política de Incentivos do Ministério da Saúde para Atenção Básica: Uma Ameaça à Autonomia dos Gestores Municipais e ao Princípio da Integralidade. Cad. Saúde Públ., Rio de Janeiro, v.18,supl., p.163-171, 2002.

MIRANDA, A. S et al.. A Importância do Treinamento Periódico dos Agentes Comunitários de Saúde frente a Enfermidades como Formar sua Atuação junto a Comunidade. Revista Eletrônica. Disponível em : < www.nutrição em pauta. com. Br $>$. Acesso em: 24 jan 2004.

MINAYO, M. C. S. O Desfio do Conhecimento : Pesquisa Qualitativa em Saúde. 5 ed. São Paulo: Hucitec, 1996. 269 p.

ORGANIZAÇÃO MUNDIAL DA SAÚDE. Declaração de Alma-Ata. Disponível em: < www. saude em movimento. com. br $>$. Acesso em: 24 jan 2004.

PEDROSA, J. I. S.; TELES, J. B. M. Consenso e Diferenças em Equipes do Programa Saúde da Família. Rev. Saúde Públ., São Paulo, v.35, n.3, p.303311, 2001.

PORTO ALEGRE. Prefeitura Municipal de Porto Alegre. Projeto Integrado: Desenvolvimento Sustentável da Lomba do Pinheiro. Porto Alegre, Julho 2003.

RODRIGUES, M. C. Fatores de (in) Satisfação e Stress Organizacional: o Caso dos Funcionários da Seguridade Social.
Revista Eletrônica. Disponível em: < www. asp. pt. /iv cong.cts $>$. Acesso em: 24 março 2004.

SANTOS, R. Alguns Conceitos para Avaliar Usabilidade. Revista Eletrônica. Disponível em: < www. unicarioca. edu. br/ design/ artigos $>$. Acesso em: 24 março 2004 .

SCHIMITH, M.D; LIMA, M.A.D.S. Acolhimento e Vínculo em uma Equipe do Programa Saúde da Família. Cad. Saúde Públ., Rio de Janeiro v.20, n.6, p.1487-1494, nov. / dez., 2004.

SOUZA, M. F. Gestão da Atenção Básica: Redefinindo Contexto e Possibilidades. Div. Saúde Debate, Rio de Janeiro, n. 21 , p. 7-14, dez. 2000.

TRAD, L. A. B et al.. Estudo Etnográfico da Satisfação do Usuário do Programa de Saúde da Família (PSF) na Bahia. Ciênc. Saúde Col., Rio de Janeiro, v.7, n.3, p.581-589, 2002.

TRIVIÑOS. A. N. S. Pesquisa Qualitativa.In: .Introdução à Pesquisa em Ciências - A Pesquisa Qualitativa em Educação. São Paulo: Atlas, 1987. Cap.5, p.116-170.

ZANETTI, C. H. G. Saúde Bucal no Programa de Saúde da Família (PSF) - Proposição e Programação. Brasília:[S.n], fev. 2000 .

\section{Endereço para correspondência:}

Departamento de Odontologia Preventiva e Social

Faculdade de Odontologia da UFRGS

Rua Ramiro Barcelos, 2492, Porto Alegre - RS

CEP: 90035-003

e-mail: emidio3@ig.com.br 